\title{
ВОССТАНИЕ НА ТЕРРИТОРИИ ВОСТОЧНОЙ РИМСКОЙ ИМПЕРИИ ПОД РУКОВОДСТВОМ ГАЙНЫ, В КОНТЕКСТЕ ВЗАИМООТНОШЕНИЙ ГЛАВНОГО МЯТЕЖНИКА С АЛАРИХОМ, СТИЛИХОНОМ И ГОТАМИ СЕВЕРНОГО ПРИЧЕРНОМОРЬЯ
}

\section{THE REBELLION ON THE TERRITORY \\ OF THE EASTERN ROMAN EMPIRE UNDER \\ THE LEADERSHIP OF GAINAS \\ IN THE CONTEXT OF THE RELATIONSHIP \\ OF THE MAIN REBEL WITH ALARIC, STILICHO AND THE GOTHS OF THE NORTHERN BLACK SEA REGION}

\section{S. Yartsev}

Summary: The article deals with the complex aspects of the relationship of the magister militum Gainas with Alaric, Stilicho and the Goths of the Northern Black Sea region on the eve and during the first months of the barbarian rebellion on the territory of the Eastern Roman Empire at the end of the 4th century. Based on a thorough analysis of the sources, the author concludes that Gainas' conspiracy became possible thanks to the break between Alaric and Eutropius. Probably, the main rebel offered Alaric's Foederati Goths more favorable conditions of residence and service in the Empire than those that Eutropius, the praepositus sacri cubiculi and the favorite of the Emperor, could provide to them. The author proposes a new concept of these events based on the idea of a radicalization of the rebellion, its orientation, both against Eutropius, and later against Stilicho. Apparently, this was the only way to win Alaric's Goths on their side, tearing them away from the alliance with Eutropius. At the same time, it is possible that it could also be a question of organizing a campaign of the Foederati Goths to the West against the army of Stilicho. In case of it being successful, the barbarians could well be promised lands for resettlement on the Apennine Peninsula. It seems right to suggest that the Goths of the Northern Black Sea region could have also agreed to participate in such a military expedition. Badly affected by the Hunnic invasion, they wanted to free themselves from the power of the nomads, knowing full well that to achieve this in the new conditions, it was possible only by moving to the territory of the Empire. Considering the fact of the main rebel having no other other allies, with the support of which he could effectively achieve his goals, the author concludes that only a powerful and unquestioningly obedient barbaric army could become Gainas' main support in his aspirations and could lead the powerful Goth to victory over his numerous enemies. Probably, Gainas planned to appoint his people of barbaric origin to all the central posts in the state. Thus achieved control over all key government departments would allow him to rule the Empire virtually single-handedly, relying on the faithful Goths.

Keywords: The Roman Empire, Stilicho, Eutropius, Alaric, Gainas, Tribigild, rebellion, the Goths.

\author{
Ярцев Сергей Владимирович \\ Д.и.н., дочент, Тульский государственный педагогический \\ университет им Л.Н. Толстого \\ s-yartsev@yandex.ru
}

Аннотация: Статья посвящена сложным аспектам взаимоотношений военного магистра Гайны с Аларихом, Стилихоном и готами Северного Причерноморья, накануне и в первые месяцы восстания варваров на территории Восточной Римской империи в конце IV в. На основе тщательного анализа источников, автор приходит к выводу, что заговор Гайны, стал возможен благодаря разрыву Алариха и Евтропия. Вероятно, готам-федератам Алариха главным мятежником были предложены более выгодные условия проживания и службы в империи, чем те, которые смог им предоставить препозит священной опочивальни и фаворит императора Евтропий. Автор предлагает новую концепцию указанных событий, в основе которой лежит идея радикализации мятежа, его направленности, как против Евтропия, так и в дальнейшем, против Стилихона. По-видимому, только таким способом можно было окончательно привлечь на свою сторону готов Алариха, оторвав их от союза с Евтропием. При этом не исключено, что речь могла идти также и об организации похода готов-федератов на Запад против армии Стилихона, в случае успеха которого варварам вполне могли быть обещаны земли для расселения на Апеннинском полуострове. Представляется, что согласиться на участие в такой военной экспедиции могли и готы Северного Причерноморья. Сильно пострадавшие от гуннского нашествия, они желали освободиться изпод власти кочевников, прекрасно осознавая, что добиться этого в изменившихся условиях, было возможно, только переселившись на территорию империи. Учитывая полное отсутствие у главного мятежника других союзников, с опорой на которых он мог бы эффективно достичь поставленных целей, автор приходит к выводу, что только мощная варварская и беспрекословно подчиняющаяся Гайне армия, могла стать главной опорой его устремлений и привести могущественного гота к победе над своими многочисленными врагами. Вероятно, Гайна планировал назначить на все центральные посты в государстве своих людей варварского происхождения. Достигнутый, таким образом, контроль над всеми ключевыми государственными ведомствами, позволил бы ему фактически единолично править империей с опорой на верных готов.

Ключевые слова: Римская империя, Стилихон, Евтропий, Аларих, Гайна, Трибигильд, восстание, готы. 
C обытия, связанные с восстанием готов Гайны и Трибигильда на территории Восточной Римской империи в конце IV в., до сих пор продолжают вызывать интерес среди ученых. Однако, несмотря на значительное количество трудов, еще многие вопросы истории римского государства данного периода, остаются нерешенными $[1 ; 2 ; 3 ; 4 ; 5 ; 6 ; 7 ; 10 ; 11 ; 13 ; 16 ; 18 ; 20]$. При этом наиболее сложной проблемой продолжает считаться характер взаимоотношений Гайны с Аларихом, Стилихоном и варварами, пребывающими за пределами Римской империи. Положение усугубляется еще и тем, что исходя из фрагментарности источников и противоречивости дошедших до нас сведений, некоторые исследователи, не уделяют этому важнейшему аспекту кризиса гото-римских отношений, достаточного внимания. Однако без учета данных особенностей, преодолеть имеющиеся противоречия в источниках и разрешить все сложные вопросы истории готского мятежа, вряд ли будет возможно. Необходим глубокий анализ целей и позиций всех сторон интересующего нас конфликта, с помощью которого у нас появляется возможность продвинуться вперед в изучении данного знакового периода истории поздней империи. Во всяком случае, вряд ли после этого можно будет рассматривать восстания Гайны и Трибигильда в качестве отдельных исторических событий, или представлять готских вождей неуверенными в себе людьми, действующими спонтанно, а не по заранее разработанному плану.

Разумеется, ключевые противоречия римского общества, которые и привели к готскому мятежу, возникли не в одночасье. Они явно уходят своими корнями в сложную ситуацию, которая сложилась в империи еще задолго до событий, связанных с восстанием Гайны. Скорее всего, определенную роль здесь сыграла военная кампания Стилихона в Греции в 397 году и особенно ее неоднозначные последствия, когда вместо наступления мира, резко обострились все противоречия между основными действующими силами в империи. В этой связи, логично предположить, что восстание Гайны также стало следствием данного греческого похода. На это указывает, хотя бы то, что Стилихону, после греческой кампании, необходимо было срочно предпринять меры по укреплению своей власти, пошатнувшейся после очередного поражения на Востоке. По всей вероятности, важнейшей частью таких действий и должно было стать преодоление кризиса отношений с Востоком. Тем более, что после 397 года ситуация на этот счет осложнилась, и Стилихону вновь приходилось искать соразмерные ответы на откровенно враждебные деяния Константинополя. Дело дошло даже до того, что правящая верхушка восточной части империи, решила поддержать восставшего против Запада Гильдона (Claud. Stil., 269-313). Возможно, что покушение на Стилихона в это время [16, р. 134], также было, каким-то образом, связано с обострением внутреннего противостояния в империи. В таком случае, можно говорить, что в конце 90-х гг. IV в., произошла новая активизация затянувшегося конфликта между Западом и Востоком. Вероятно, в контексте данного противостояния необходимо рассматривать и продолжающееся настойчивое отстаивание Стилихоном своих притязаний на parens над всей империей, что не только укрепляло его власть на Западе [21, р. 148], но и предоставляло ему возможность взять реванш в восточной части империи.

Особенности внешней и внутренней политики Стилихона, действительно, указывают на стремление последнего к установлению единоличной власти на территории всей Римской империи. Особенно важным здесь представляется продолжение успешных военных преобразований и достижение полного контроля Стилихона над армией [13, с. 176-186]. При этом хорошей демонстрацией возросших боевых качеств западных римских воинских подразделений, стала довольно успешная военная кампания в Северной Африке против мятежного Гильдона в конце 397 года. Командование африканской экспедицией Стилихоном было поручено брату Гильдона - Масцезелю. Расчет действительно оказался верным. В решающий момент многие из восставших перешли на сторону прибывшего из Италии брата [13, с. 166-175] и Гильдону пришлось задушить «себя своей же собственной рукой. Так Масцизель одержал победу без войны и без кровопролитной мести» (Marcell. Chron., 398).

После такой сокрушительной победы и восстановления поставок зерна в Рим, фактический правитель Запада, казалось бы, должен был сразу же, без замедления, перейти к решению проблемы связанной с Евтропием. Тем более что положение последнего после победы Стилихона в Африке, пошатнулось. Евтропий действительно не захотел или не смог помочь Гильдону, что предсказуемо ударило по его репутации [13, с. 175].

Тем не менее, после африканской кампании мы не наблюдаем всплеска активности Стилихона на восточном направлении имперской политики. Более того, судя по явному указанию западного властителя своему придворному поэту Клавдиану, последний в авторской поэме «Война против Гильдона», зачем-то специально отделил мятеж в Африке от конфликта между правителями Запада и Востока Римской империи. Не вызывает сомнений, что данная особенность информационной войны против Евтропия, являлась частью глубоко продуманной стратегии Стилихона, о которой нам ничего точно не известно. Вряд ли, конечно, главной ее целью являлось примирение, якобы оставленное без внимания на Востоке [16, р. 124]. Даже отказ Стилихона от своей кандидатуры на назначение консулом на Западе [13, с. 190-191], не дает нам повод считать его отрекшимся от своих экспансионистских планов на Востоке. На фоне 
объявления правителя Запада hostis publicus, конфискации его имущества и ответного желания последнего взять реванш за поражение 397 года, вернее предположить, что выше обозначенная особенность произведения Клавдиана «Война против Гильдона» была вызвана стремлением Стилихона отвести от себя подозрение от готовящегося удара по Евтропию. Видимо совсем не случайно Зосим оговорился, что «с этого времени вражда между Евтропием и Стилихоном стала скрытой и малоизвестной, но, тем не менее, они были настоящими врагами» (Zosim., V, 12, 1). Исходя из этого, можно предположить, что восстание Гайны, на самом деле являлось разработанной на Западе, операцией, в ходе которой Евтропий должен был отстранен от власти, а Стилихон восстановлен в правах. Собственно ее началом стал мятеж в воинских подразделениях восточной армии, организация которого была возложена на Гайну - наиболее известного и проверенного человека Стилихона на Востоке. Гайне действительно удалось вызвать волнения среди соплеменников - готских федератов, что, правда не составило особого труда, учитывая недовольство Евтропием не только самим Гайной (Zosim., V, 13, 1), но и его ближайшим родственником Трибигильдом (Socr., I, VI, 6; Soz., VIII, 4), также не получившим достойной награды за свою службу (Claud. Eutrop., II, 170-180). Задействие такого «отчаянного смельчака, готового на любое лихое дело, и командовавшего по приказу императора варварскими войсками, стоявшими во Фригии» (Zosim., V, 13, 2), безусловно, отводило тень подозрения с самого Гайны, который, по-видимому, должен был в ключевой момент мятежа склонить императора к необходимости приглашения Стилихона на Восток для наведения порядка. Это следует из текста Клавдиана, который в одном из мест своей поэмы явно стараясь выдать желаемое за действительное, утверждал, что Стилихона на Востоке «все уж хотят, чтоб явился он к ним, и в прежних злодействах каются; средь валов сокрушительных браней звездою чают его, и виновны и праведны ждут его вместе...» (Claud. Eutrop., II, 500-515). Не вызывает сомнения, что при таком развертывании событий и появлении Стилихона в Константинополе с западной армией, дни Евтропия, во всяком случае, на своем высоком посту, были бы сочтены. Надо сказать, что данный план был вполне реалистичным и при его выполнении Стилихон вполне мог добиться своей главной цели - получения права parens principum объединенной империи.

Однако не все здесь выглядит так однозначно. Вероятно начиная еще с весны 399 года, как только Трибигильд вступил в сговор с человеком Стилихона - Гайной (Zosim., V, 13, 2; Socr., I, VI, 6; Soz., VIII, 4; Eunap., 75-76), последний явно начал вести двойную игру, все, более стараясь ориентироваться уже на свои личные, корыстные интересы. Косвенно на это указывают особенности ситуации, сложившейся уже в самом начале готского мя- тежа, когда летом 399 г. «Трибигильд покинул Константинополь, делая вид, что направляется во Фригию, чтобы сделать смотр своим варварам. Но когда он принял командование над ними, то набросился на все, что смог найти, убивая мужчин, женщин и детей, и грабя все на своем пути. В короткое время Трибигильд собрал такую массу рабов и изгнанников, так, что вся Азия оказалась в серьезной опасности. Лидия пребывала в полном разорении» (Zosim., V, 13, 3-4). Таким образом, за короткий период под угрозу нападения варваров, попал целый ряд восточных провинций Римской империи (Eunap., 75; Soz., VIII, 4). Казалось бы, Трибигильд вполне мог начать восстание по собственной инициативе, стремясь улучшить свое положение в империи. Однако то, что все эти мятежные действия в Малой Азии являлись важной частью большого заговора Гайны, свидетельствует категорический отказ Трибигильда прекратить восстание в обмен за высокую должность (Claud. Eutrop., II, 320-321). Видимо участниками заговора ему был обещан гораздо более выгодный и престижный пост в государстве, чем предложенное Евтропием место в командной иерархии восточной армии. Все это опровергает мнение о спонтанно действующем Гайне, который якобы лишь после разрастания восстания Трибигильда понял, что может использовать его в своих личных целях [13, с. 195].

Очень странно, но в такой ответственный момент император отправляет Гайну полководцем во Фракию, где он должен был встретить врагов «если он обнаружит их», например, в случае перехода через Геллеспонт (Zosim., V, 14, 1-2). Возможно, такому решению содействовал пост регионального магистра, который был предоставлен Гайне еще Стилихоном. На реальную же войну против мятежников, почему-то был послан не имеющий боевого опыта, друг Евтропия - Лев, получивший должность comes rei militaris (Zosim., V, 14, 1-2) [13, с. 195]. Он хотя и стал военным магистром, однако не принадлежал к числу талантливых полководцев (Eunap., 76; Claud. Eutrop., II, 370-390). Таким образом, в тексте Зосима явно присутствует слабо аргументированная и во многом искусственная версия отправки Гайны в противоположную сторону от районов, охваченных восстанием. Следует также заметить, что Аларих в Иллирике был всем обязан Евтропию, который в свою очередь, сам теперь мог рассчитывать на помощь готской армии в тяжелой для него ситуации. Может поэтому и потребовалось пребывание Гайны во Фракию, ведь именно находясь там, легче всего было договориться с Аларихом [20, р. 155; 13, с. 195]. Тогда факт пребывания Гайны в данной провинции в самом начале готского мятежа и стал причиной искусственных построений Зосима, пытающегося по-своему объяснить этот факт. Но если это так, то сразу же после начала мятежа и переговоров с Аларихом, Гайна должен был подойти из Фракии со своими силами к Константинополю, по крайней мере, для ложной демонстрации 
своей готовности вступления в борьбу с мятежниками. Судя по дошедшим до нас сведениям, похоже, что именно так все и произошло в действительности. Мы видим, что довольно быстро (возможно после смерти Льва?) воинские силы Гайны, были переброшены к столице, где находились непосредственно «под Константинополем» (Zosim., V, 14, 4). После этого они свободно переправились в Азию, якобы уже для непосредственной войны с мятежниками (Zosim., V, 15, 3).

Таким образом, судя по имеющимся у нас сведениям, причина переброски воинских подразделений Гайны от Фракии до азиатских провинций, была обусловлена внутриполитическими факторами, а не в связи с возникновением внешней угрозы римским границам. Данное обстоятельство, по нашему мнению, может пролить свет на некоторые особенности взаимоотношений Стилихон Евтропий - Аларих - Гайна.

Начнем с того, что относительно близкое расположение Фракии к римскому лимесу, сразу же позволяет предположить о контактах Гайны в период пребывания его в этой провинции, не только с Аларихом, но и с варварами, живущими за пределами Римской империи. Правда, точнее ответить на этот вопрос, возможно только через определение роли готов Алариха и варваров Северного Причерноморья в интересующих нас событиях. Напомним, что еще Т.С. Бернс задавался вопросом, почему Аларих, странным образом дистанцировался от готского мятежа и не помог Евтропию, с которым заключил договор и кому был обязан своим высоким положением в государстве [15, р. 176-179]. Дело в том, что смерть Евтропия, однозначно вела к денонсации договора и потере готами своих вновь приобретенных территорий в Иллирике. Поэтому отказ готов от помощи Евтропию, однозначно свидетельствует о достигнутой новой договоренности между Аларихом и Гайной, разумеется, на более выгодных для варваров условиях. В этой связи, однозначно нельзя считать Алариха и его воинов «обременительными изгоями» [8, с. 315]. В сложившейся ситуации, по нашему мнению, ключевую роль в событиях готского восстания, стали играть совсем другие факторы. Так, если действительно основой заговора Гайны, составил разрыв Алариха и Евтропия, то в этом случае можно говорить о радикализации мятежа, его направленности как против Евтропия, так и против Стилихона. По-видимому, только таким способом можно было окончательно привлечь на свою сторону готов Алариха, оторвав их от союза с Евтропием. Не исключено, что в этом случае, речь могла идти об организации похода готов на Запад против армии Стилихона, в случае успеха которого варварам вполне могли быть обещаны земли для расселения на Апеннинском полуострове. Представляется, что согласиться на участие в такой военной экспедиции могли и готы Северного Причерно- морья. Сильно пострадавшие от гуннского нашествия, они желали освободиться из-под власти кочевников, прекрасно осознавая, что добиться этого в изменившихся условиях, было возможно, только переселившись на территорию империи. При этом обеспечить варварам относительно безопасный подход к римским границам, могло обеспечить только всеобщее успешное восстание готов против своих господ.

В пользу привлечения Гайной готов Северного Причерноморья в качестве ключевой силы во внутриполитическом противостоянии в государстве, свидетельствует полное отсутствие у главного мятежника других союзников, с опорой на которых он мог бы эффективно достичь поставленных целей. На римском Востоке не было ни единой социальной силы, которая видела бы в готах своих перспективных и верных друзей. Практически везде пришельцы представляли собой чужеродную социальную структуру, а распространившееся среди варваров арианство еще более способствовало их отчуждению от местного античного населения [9, с. 38-39].

Напомним, что наиболее активно в борьбе против Гайны выступала римская антиготская партия (также враждебно настроенная и против Евтропия). Ее представители придерживались довольно радикальных антиварварских позиций. Главой антиготской партии являлся Аврелиан, поддерживаемый императрицей Евдоксией. Это была та часть господствующего класса, которая стремилась всеми силами сохранить позднеантичный городской строй при дальнейшей централизации власти в государстве [5, с. 26]. Ей противостояла группировка Евтропия в основном состоящая из представителей торгово-ростовщической знати столицы и крупных эмпориев [4, с. 79]. Удивительно, но даже феодосианцы, несмотря на репрессии и сильное давление от Евтропия, не видели для себя особенных выгод от союза с Гайной и готами. По большей части (хотя и в силу обстоятельств), они более шли на сотрудничество с Евтропием, чем с варварами. То обстоятельство, что римская часть восставшей под руководством Гайны армии, была сориентирована последним именно на остатки феодосианцев [3, с. 91-92], более свидетельствует о безысходности руководителя восстания, чем о наличии общих точек соприкосновения между ними. Даже проготское правительство Кесария, которое фактически привел к власти Гайна, старалось использовать варваров, только в случае необходимости с целью реализации исключительно своих планов [5, с. 27]. Вот почему, как верно подметила А.А. Чекалова, несмотря на то, что Гайна владел домом в Константинополе, где он жил с женой и детьми, имел связи в верхах римского общества, он так и остался представителем того варварского элемента, который в гордом сознании своей силы властно вступал в совершенно чуждую ему по культуре и традициям среду. По этой причине любая 
его попытка стать ближе к верховной власти, не могла принести ничего, кроме кровопролития и замешательства $[14$, с. 69].

Таким образом, опереться в своей борьбе за власть в империи, Гайна мог только на соплеменников, большая часть которых в данное время находилась под властью гуннов и пребывала за пределами государства. Однако для появления в империи новых мигрантов, необходимо было помочь им обрести свободу от власти кочевников. С этой целью у Гайны не было особого выбора, кроме как спровоцировать на подчиненной гуннам территории восстание готов против своих новых господ. Вот почему, не такой уж аллегорией [3, с. 92] выглядит приглашение Гайны на территорию империи целого готского народа, сведение о котором сохранилось у некоторых авторов. При этом речь могла идти именно о грейтунгах, так как известно, что Трибигильд являлся дуксом конницы (Claud. Eutrop., II, 176-177), а последняя обычно соотносится именно с данной готской группировкой варваров [7, с. 245]. По всей видимости, находясь во Фракии Гайна реально призвал «единоплеменников своих готфов из их стран в земли римские и близких к себе между ними ставил сотниками и тысяченачальниками» (Soz., VIII, 4,1). Исходя из контекста сообщений источников, речь здесь идет не просто об очередном наборе наемников, а о явной организации нового массового переселения готов Северного Причерноморья на территорию Римской империи. По нашему мнению, необходимо со всей серьезностью отнестись к данной информации, несмотря на всю специфику и тенденциозность наших источников. Дело в том, что Гайна похоже на самом деле «забылся и не мог ограничить своих замыслов», так как «он призвал к себе весь готский народ из его отечества и своим приближенным старался доставить в войске начальственные должности» (Socr., VI, 6). Конечно, сложившаяся непростая ситуация в империи, отчасти оправдывала такой радикальный подход высокопоставленного гота в борьбе за власть. Дело в том, что только мощная варварская и беспрекословно подчиняющаяся Гайне армия, могла стать главной опорой его устремлений и привести его к победе над своими многочисленными врагами. В этой связи, очевидно, что именно Гайна являлся главным вдохновителем и идейным организатором восстания, которое должно было охватить, не только готов-федератов, но и всех его соплеменников находившихся в это время под властью гуннов. Предполагать, что в этой ситуации он действовал спонтанно, присоединившись к Трибигильду только на определенном этапе, было бы явной ошибкой [16, р. 134-135].

Исходя из всего вышесказанного, а также учитывая масштаб заговора и поставленных задач, так или иначе связанных с планами переселения в империю большой массы варваров, можно постараться уточнить главную цель Гайны, которую он хотел добиться посредством восстания, тем более что на этот вопрос до сих пор не существует единой, общепризнанной точки зрения. Так, например, сведение деятельности Гайны исключительно к банальному грабежу, вряд ли будет считаться уместным, так как последний, получивший высшую воинскую должность в империи, не стал бы заниматься откровенным воровством и разбоем. В какой-то степени можно объяснить специфику некоторых сведений о его восстании в источниках, контаминацией с событиями нападения на Рим готов Алариха [17, р. 205-206], но представить Гайну грабителем, невозможно. Вызывает вопросы и довольно распространенная версия, что Гайна, на самом деле, не только не хотел быть императором [2, с. 216], но и вообще, по большому счету, не стремился к власти в форме тирании, а лишь хотел занять положение, которое занимал Стилихон на Западе [18, р. 197; 19, р. 197]. Главный недостаток данной гипотезы заключается в том, что она совсем не проясняет ситуацию, сложившуюся в государстве на заключительном этапе восстания к 400 г. Во всяком случае, мы не сможем, опираясь на данную гипотезу ответить на вопрос, зачем Гайне в это время понадобились волнения в самой столице. Поэтому, учитывая многочисленные утверждения источников о стремлении Гайны к тиранической власти в империи (Zosim., V, 17, 4-5, 18, 9-10; Socr., VI, 6; Soz., VIII, 4; Theodor., $\mathrm{V}, 32)$, по нашему мнению, вернее будет согласиться c данным мнением и допустить, что могущественный гот, все же хотел установить тираническое правление в римском государстве [14, с. 86]. При этом речь могла идти о территории всей, объединенной уже под его властью, Римской империи. Во всяком случае, только такая амбициозная цель, может объяснить масштабность запланированного переселения готов Северного Причерноморья на римские земли. Разумеется, Гайна был нацелен на захват верховной власти, а не на уничтожение государства, в котором он имел довольно высокий статус. Видимо прав был Э.А. Томпсон, когда говорил, что мятежники, в первую очередь, хотели укрепить достигнутое положение, увеличить богатства и усилить свое влияние внутри римского мира [12, с. 40]. Другими словами, захватить «верховную власть над Римской империей» (Soz., VIII, 4), Гайна планировал посредством назначения на все центральные посты в государстве своих людей варварского происхождения. Достигнутый контроль над всеми ключевыми государственными ведомствами, позволил бы ему фактически единолично править империей с опорой на верных готов. Учитывая, что стать такой доминирующей силой в государстве можно было только при значительном увеличении количества варваров на римских землях, именно данную проблему и предполагала решить новая волна миграции на территорию империи. 


\section{ЛИТЕРАТУРА}

1. Богданов Д.Е. Борьба западного и восточных дворов Римской империи в конце IV века // Научные ведомости БелГУ. Серия История. Политология. 2017. №22. C. 41-45.

2. Вольфрам Х. 2003. СПб.: Ювента, 2003.656с

3. Глушанин Е.П. Военная знать ранней Византии. Барнаул: Алт. кн. изд-во, 1991. 246 с.

4. Козлов А.С. Борьба между политической оппозицией и правительством Византии в 395-399 гг. // Античная древность и средние века. Свердловск, 1976. Вып. 13. С. 68-82.

5. Козлов А.С. Основные черты политической оппозиции правительству Византии в 399-400 гг. // Античная древность и средние века. Свердловск, 1979. Вып. 16. С. 23-31.

6. Коньков Д.С. Готы на территории Римской империи: трансформация этно-потестарной идентичности. Северск: Изд-во СТИ НИЯу МИФИ, 2011. 151 с

7. Коньков Д.С. Готы и империя: восстание Гайны как кризис идентичности // Известия Томского политехнического университета. 2012. Т. 321. №6. C. $244-249$

8. Коньков Д.С. Аларих между Востоком и Западом: в поисках места в империи (399-402 гг.) // Известия Томского политехнического университета. 2013. Т. 323. №6. С. 314-319.

9. Корсунский А.Р., Гюнтер Р. Упадок и гибель Западной Римской империи возникновение германских королевств (до середины VI в.). М.: Изд-во МГу, 1984. 256 c.

10. Ляховская 0.В. Готы в Константинополе: мятеж Гайны 399-400 гг. // Научные ведомости БелГУ. Серия История. Политология. Экономика. Информатика. 2011. №13. Вып. 19. С. 35-38.

11. Сиротенко В.Т. Борьба Западной Римской империи и Византии за префектуру Иллирик в 395-425 гг. и ее последствия // Античная древность и средние века. Свердловск, 1972. Вып. 8. С. 73-88.

12. Томпсон Э.А. Римляне и варвары. Падение Западной империи. СПб.: Ювента, 2003. 288 с.

13. Хьюджес Й. Стилихон. Вандал, который спас Рим. М.: Изд-во «Клио», 2017. 352 с.

14. Чекалова А.А. Варварский элемент в Византии (IV-V века) // Цивилизация и варварство: механизмы, инструменты и субъекты взаимодействия. М.: Аквилон, 2014. Вып. III. С. 75-102.

15. Burns T. Barbarians within the gates of Rome: a study of Roman military policy and the barbarians, ca. 375-425 A.D. Bloomington: Indiana University Press, 1994. $417 \mathrm{p}$.

16. Cameron A. Claudian: Poetry and Propaganda at the Court of Honorius. Oxford: Clarendon press, 1970.508 p.

17. Cameron A., Long J., Sherry L. Barbarians and Politics at the Court of Arcadius (The transformation of the classical heritage XIX). Berkeley: University of California Press, 1993. $411 \mathrm{p}$.

18. Demougeot E. De l'unité à la division de l'empire romain, 395-410. Paris: Adrien-Maisonneuve, 1951. 618 p.

19. Heather P.J. Goths and Romans, 332-489. Oxford: Clarendon Press, 1991. 378 p.

20. Liebeschuetz J.H.W.G. Barbarians and Bishops: Army, Church and State in the Age of Arcadius and Chrysostom. Oxford: Clarendon Press, 1990. 312 p.

21. Williams S., Friell G. Theodosius: The Empire at Bay. London: Batsford, 1994. 238 p. 